\title{
ANÁLISE DO COMPORTAMENTO E EXPERIMENTAÇÃO: POSSIBILIDADES DE AVANÇOS NO CONHECIMENTO SOBRE FENÔMENOS PSICOLÓGICOS ${ }^{1}$
}

\author{
Juliane Viecili* \\ Olga Mitsue Kubo\#
}

\begin{abstract}
Motivação ou operação estabelecedora? Depressão ou desamparo aprendido? Força da resposta ou momento comportamental? Você sabe em que a ciência psicológica avançou na definição de seus processos básicos? Acompanhar o desenvolvimento do conhecimento produzido em Psicologia é fundamental para o psicólogo ampliar sua percepção sobre os fenômenos e processos psicológicos a fím de produzir intervenções significativas para a sociedade. O livro Análise do Comportamento: Pesquisa, Teoria e Aplicação, organizado por Josele Abreu-Rodrigues e Michela Rodrigues Ribeiro, no ano de 2005, possibilita uma atualização conceitual sobre fenômenos básicos estudados em Psicologia, na perspectiva da Análise Experimental do Comportamento, e apresenta exemplos de atividades profissionais relacionadas aos conceitos discutidos na produção de conhecimento e de intervenção.

O livro enseja ao leitor uma incursão na história da Psicologia. Os capítulos são organizados de forma a apresentarem o desenvolvimento de conceitos relacionados aos fenômenos e processos psicológicos, possibilitando ao leitor avaliar as contribuições mais recentes em Psicologia, como processos de "motivação", “aprendizagem", “depressão". Os autores dos capítulos tiveram a preocupação de contextualizar o conhecimento produzido ao longo da história da Psicologia e da Análise do Comportamento principalmente. Essa contextualização é extremamente pertinente, pois permite ao leitor identificar as
\end{abstract}

alterações ocorridas com o conceito em decorrência de avanços no conhecimento produzido sobre os fenômenos e processos psicológicos. Por exemplo, Cristiano Valério Santos, no capítulo Momento Comportamental, indica que, tradicionalmente, estudos sobre a persistência da resposta têm sido tratados como força da resposta, porém o termo vem sendo substituído pelo conceito de momento comportamental, por demonstrações de que o fenômeno psicológico estudado envolve uma operação de adição da taxa da resposta e da resistência à mudança. Outro bom exemplo é o conceito de motivação discutido por Rachel Nunes da Cunha e Geison Isidro-Marinho. Os autores, por meio de uma avaliação histórica do conceito e de pesquisas sobre um fenômeno referido na literatura como "motivação", consideram que operação estabelecedora é uma nomenclatura mais precisa para indicar um evento ambiental que altera a eficácia reforçadora de um estímulo, bem como para diminuir a ambigüidade que está relacionada com a utilização coloquial desse termo. Essas denominações apresentadas pelos autores possibilitam avaliar mais precisamente qual é o fenômeno que ocorre em relação ao conceito apresentado.

Um aspecto bastante chamativo que caracteriza a estrutura geral de apresentação dos capítulos é que a fundamentação para definir conceitos "velhos ou novos" estudados no contexto da Psicologia e da Análise do Comportamento é calcada em dados

1 Abreu-Rodrigues, J. \& Ribeiro, M. R. (2005). Análise do comportamento: pesquisa, teoria e aplicação. Porto Alegre: Artmed.

* Professora do curso de Psicologia da Universidade do Planalto Catarinense e Professora Substituta do Departamento de Psicologia da Universidade Federal de Santa Catarina.

\# Professora do Departamento de Psicologia e do Programa de Pós-Graduação em Psicologia da Universidade Federal de Santa Catarina. 
produzidos experimentalmente. Se, por um lado, a demonstração experimental possibilita a garantia de alto grau de confiabilidade no conhecimento produzido, por outro, requer do leitor um repertório mínimo ou familiaridade com pesquisas experimentais para "degustar" com prazer essa obra. Esse fato ocorre porque, na apresentação, feita pelos autores, da sistematização de pesquisas experimentais, básicas e aplicadas, que foram realizadas ao longo da história da Psicologia e que contribuem para a compreensão e conceituação dos fenômenos e processos psicológicos avaliados, denominações técnicas são usuais. Por exemplo, João Claudio Todorov e Elenice S. Hana, ao descreverem um experimento a fim de avaliarem a quantificação de escolhas e preferências, utilizam terminologias como "contingência de atraso de reforço para respostas de mudança (COD) no desempenho de pombos mantidos por esquemas conc VI VI (...)"; assim como Cristiano V. dos Santos descreve "vigorava um esquema VI de 120 s e a primeira resposta após o término do intervalo iniciava um atraso não sinalizado de $3 \mathrm{~s}$ ou $8 \mathrm{~s}$ (...)". Essa terminologia técnica é constante no livro e necessita ser compreendida pelo leitor para que este seja capaz de avaliar a contextualização histórica, o desenvolvimento e as contribuições apresentadas no estudo de fenômenos e processos psicológicos que caracterizam os conceitos apresentados.

O conhecimento produzido por meio de pesquisa amplia a percepção dos profissionais de Psicologia sobre os aspectos que constituem e influenciam fenômenos e processos psicológicos. Ao apresentarem as pesquisas no livro, os autores evidenciam o conhecimento já disponível sobre esses fenômenos e processos, ao mesmo tempo possibilitam identificar em que é possível avançar esse conhecimento. Dessa forma, quanto mais aspectos são conhecidos por psicólogos (e mais relações entre esses aspectos), maior é a possibilidade de serem feitas novas (outras) descobertas e relações entre os aspectos que constituem um fenômeno e maior será o grau de confiabilidade de intervenções profissionais.

Outro aspecto interessante do livro é que as pesquisas descritas pelos autores não se restringem a experimentos realizados em grandes centros internacionais. As pesquisas sobre fenômenos e processos psicológicos que caracterizam os conceitos apresentados no livro foram realizadas no exterior e no Brasil, evidenciando o crescimento da pesquisa nacional sobre esses fenômenos e processos. É interessante notar a quantidade de pesquisas realizadas no país (algumas vezes experimentos de delineamentos complexos com utilização de equipamentos sofisticados) apresentadas pelos autores e avaliar as implicações dessa incursão na pesquisa para o psicólogo brasileiro. Entre essas implicações, é possível considerar a ampliação da percepção do psicólogo brasileiro sobre os fenômenos e processos psicológicos, a ampliação da eficácia de intervenções, além de ser possível estabelecer relações de construção constante (e prazerosas!) do conhecimento à luz do método da Ciência.

Pesquisar e intervir são (ou deveriam ser!) dois aspectos intimamente relacionados na prática profissional do psicólogo e o livro evidencia isso. Para facilitar a compreensão dos conceitos apresentados no livro, os autores indicam atividades profissionais de intervenção relacionadas aos fenômenos e processos psicológicos a que os conceitos se referem. A demonstração de "aplicação dos conceitos" favorece aos leitores a generalização do conhecimento produzido, muitas vezes em laboratório, para a realidade social de atuação profissional. Essa demonstração também é importante para avaliar que mesmo o que é produzido em situações controladas não é descontextualizado ou diferente da realidade, favorecendo uma aproximação entre produção e aplicação do conhecimento. Alessandra R. Albuquerque e Raquel M. de Melo, após apresentarem pesquisas básicas e aplicadas em equivalência de estímulos (principalmente em aprendizagem de leitura e escrita), avaliam como a equivalência de estímulos pode ser aplicada na clínica psicológica como um recurso para identificar as situações de discriminação condicional e intervir de modo a priorizar o reforçamento de comportamentos alternativos e não relacionados ao problema.

Os autores se esmeram em tornar as conceituações sobre os fenômenos psicológicos mais precisas, mas, apesar desse esforço, alguns vícios lingüísticos parecem persistir. No decorrer do livro, é possível identificar algumas contradições em relação ao conceito de comportamento. Essas contradições se referem à utilização da definição de comportamento ora como uma relação entre ambiente e organismo, ora como parte dessa relação, como sinônimo de resposta (ou ação) do organismo. A falta de padronização da linguagem pode gerar incompreensões acerca do fenômeno psicológico que já foram superadas pelo conhecimento produzido em Psicologia (como propuseram Skinner, 1969; Botomé, 2001 entre outros).

Avançar, precisar, melhorar o conhecimento sobre fenômenos são desafios constantes de cientistas. Pelas contribuições à ciência psicológica, o livro organizado por Josele Abreu-Rodrigues e Michela Rodrigues 
Ribeiro provavelmente se tornará uma referência na literatura de Psicologia no Brasil. O livro apresenta o desenvolvimento e as inovações conceituais fundamentadas na demonstração experimental dos fenômenos e processos psicológicos, com pesquisas realizadas no país. A demonstração experimental possibilita um grau de confiança elevado no conhecimento produzido e amplia a percepção dos profissionais sobre os aspectos constitutivos do fenômeno psicológico, fato que provavelmente implica em intervenções mais eficazes. Por analisar, caracterizar e demonstrar o desenvolvimento de conceitos básicos em Psicologia é que o livro Análise do Comportamento: pesquisa, teoria e aplicação merece ser lido por psicólogos, e em especial por analistas do comportamento, preocupados com a atualização de sua prática profissional. Vale a pena conferir.

\section{REFERÊNCIAS}

Botomé, S.P. (2001). A noção de comportamento. Em H.P.M. Feltes \& U. Zilles (Orgs). Filosofia: diálogo de horizontes.(pp.687-708)Caxias do Sul: EDUCS/EDIPUCRS,

Skinner, B.F. (1969). Contingencies of reinforcement. New York: Appleton-Century-Crofts.

Recebido em 15/03/2006 Aceito em 30/03/2006

Endereço para correspondência: Juliane Viecili. Universidade Federal de Santa Catarina, Campus Trindade, Programa de Pósgraduação em Psicologia, CEP 88040-500, Florianópolis-SC. E-mail: jviecili@ gmail.com 